\title{
Absorção e redução de nitrato em duas cultivares de arroz na presença de alumínio
}

\author{
Gilberto Costa Justino $^{(1)}$, José Cambraia ${ }^{(1)}$, Marco Antonio Oliva( ${ }^{(2)}$ e Juraci Alves de Oliveira(1)
}

\begin{abstract}
(1)Universidade Federal de Viçosa (UFV), Dep. de Biologia Geral, Av. P.H. Rolfs s/noo, CEP 36571-000 Viçosa, MG. E-mail: gilcosjust@hotmail.com, cambraia@ufv.br, jalves@ufv.br (2)UFV, Dep. de Biologia Vegetal. E-mail: moliva@ufv.br
\end{abstract}

Resumo - O objetivo deste trabalho foi estudar os efeitos do alumínio (Al) sobre a absorção e a redução de nitrato, em duas cultivares de arroz: Fernandes (tolerante) e Maravilha (sensível), expostas a 0 e $500 \mu \mathrm{M}$ de Al. Depois de 21 dias de crescimento, foram determinados o comprimento, a produção de matéria seca, os teores de $\mathrm{Al}$ e de nitrato e a atividade in vitro da redutase do nitrato (RN), nas raízes e na parte aérea, bem como as constantes cinéticas de absorção de nitrato pelas raízes. O Al reduziu o crescimento em comprimento e a produção de matéria seca, nas duas partes das plantas, apenas da cultivar Maravilha. Os teores de Al aumentaram nas raízes e parte aérea das plantas nas duas cultivares, enquanto o teor de nitrato sofreu redução apenas nas raízes da cultivar Maravilha. A $\mathrm{V}_{\text {max }}$ não se modificou, enquanto o $\mathrm{K}_{\mathrm{m}}$ da absorção de nitrato diminuiu cerca de $11 \%$ na cultivar Fernandes e aumentou 310\% na Maravilha. Em presença de Al, houve redução na atividade da RN nas raízes das duas cultivares, e na parte aérea apenas da cultivar Maravilha. A cultivar tolerante foi mais eficiente na absorção e na redução de nitrato, o que indica que esses processos são importantes componentes da tolerância ao Al em arroz.

Termos para indexação: Oryza sativa, nitrogênio, redutase do nitrato, tolerância ao Al.

\section{Uptake and reduction of nitrate in two rice cultivars in the presence of aluminum}

\begin{abstract}
The objective of this work was to evaluate the effects of $\mathrm{Al}$ on the nitrate uptake and reduction in two rice cultivars, Fernandes (Al tolerant) and Maravilha (Al sensitive), exposed to 0 and $500 \mu \mathrm{M} \mathrm{Al}$. After 21 days of $\mathrm{Al}$ treatment, growth in size and dry matter yield, $\mathrm{Al}$ and nitrate contents and in vitro nitrate reductase activity (NR) in the tops and roots, and the kinetic constants of root nitrate uptake were determined. Aluminum reduced the growth and dry matter yield of both plant parts only in the Maravilha cultivar. Aluminum content increased in the tops and roots of both cultivars, while nitrate content decreased only in the roots of Maravilha cultivar. $\mathrm{V}_{\max }$ did not change, while $\mathrm{K}_{\mathrm{m}}$ of the nitrate uptake decreased in Fernandes by $11 \%$ and increased about 310\% in Maravilha cultivar. In the presence of Al the NR activity decreased in the roots of both cultivars, and in the leaves of Maravilha cultivar. The Al tolerant cultivar was more efficient in nitrate absorption and reduction, wich indicates that these processes could be important components of Al tolerance in rice.
\end{abstract}

Index terms: Oryza sativa, nitrogen, nitrate reductase, Al tolerance.

\section{Introdução}

O alumínio (Al) é um dos principais fatores que limitam o crescimento e a produtividade das culturas em solos ácidos. Estimativas revelam que, no mundo, aproximadamente $50 \%$ das terras aráveis e potencialmente utilizáveis para a produção de alimentos e de biomassa são ácidas e, portanto, sujeitas à toxicidade de $\mathrm{Al}$ (Kochian et al., 2004). No Brasil, em solos sob vegetação de cerrado, existe uma área de 1,8 milhão de km², ou cerca de $20 \%$ do território, que apresenta não só acidez excessiva, mas também baixos teores de $\mathrm{P}, \mathrm{Ca}, \mathrm{Mg}$ e K e elevados teores de Al trocável (Lopes, 1984).
O primeiro e mais evidente sintoma causado pela toxicidade do $\mathrm{Al}$ é a inibição do crescimento radicular (Kochian et al., 2004), que se manifesta após 30 minutos de exposição em cultivares sensíveis de milho (Llugany et al., 1995). Esse efeito pode ser resultante da modificação na dinâmica de efluxo e influxo de $\mathrm{H}^{+}$ através da membrana plasmática de raízes, conforme sugere Ahn et al. (2002). O Al penetra rapidamente no citossol, ligando-se a importantes moléculas e estruturas intracelulares (Kochian et al., 2004).

Alguns alvos preferenciais do Al parecem ser: o DNA, com o qual reage, aumentando a estabilidade de sua dupla hélice e inibindo sua replicação (Rout et al., 2001), 
microtúbulos e filamentos de actina (Kochian et al., 2004), mitocôndrias, diminuindo sua capacidade de produzir ATP e aumetando a produção de espécies reativas de oxigênio (Yamamoto et al., 2002). Além disso, o Al reage com a calmodulina, inibe a enzima fosfolipase $\mathrm{C}$, interfere com a homeostase do Ca e, portanto, com o sistema de sinalização via Ca (Jones \& Kochian, 1995). $\mathrm{O} \mathrm{Al}$, tem portanto, amplo espectro de ação sobre o metabolismo vegetal, razão pela qual, talvez, seu mecanismo de ação ainda não seja perfeitamente conhecido.

Diversos mecanismos de tolerância têm sido sugeridos para explicar as respostas das plantas a níveis tóxicos de $\mathrm{Al}$ (Kochian et al., 2004). Entre esses, o mecanismo de elevação do $\mathrm{pH}$ na rizosfera, que reduz a disponibilidade da forma $\mathrm{Al}^{3+}$, tem alcançado importância, principalmente depois que se verificou correlação entre a tolerância ao $\mathrm{Al}$ e o influxo de $\mathrm{H}^{+}$em pontas de raízes (Degenhardt et al., 1998).

Mendonça et al. (2005) utilizaram soluções nutritivas com diferentes proporções de $\mathrm{NO}_{3}{ }^{-} / \mathrm{NH}_{4}{ }^{+}$, e mostraram que a tolerância diferencial ao $\mathrm{Al}$, em duas cultivares de arroz, poderia estar associada à capacidade de elas modificarem o pH das soluções nutritivas. Trabalhos como esses têm indicado que pelo menos alguma etapa da aquisição ou do metabolismo de $\mathrm{N}$ pode estar envolvida com a tolerância das plantas ao Al.

Foi demonstrado que a absorção do nitrato é reduzida por $\mathrm{Al}$ em cultivares de sorgo (Cambraia et al., 1989), milho (Durieux et al., 1993; Purcino et al., 2003) e soja (Rufty Junior et al., 1995). O Al também afeta, significativamente, a redução e assimilação do N. Neste sentido, alguns estudos mostram que o $\mathrm{Al}$, além de reduzir a absorção do nitrato, reduz a atividade da redutase do nitrato (RN) (Cambraia et al., 1989; Purcino et al., 2003). Em soja, entretanto, não foi observado efeito do Al (Rufty Junior et al., 1995), e noutras espécies, até mesmo pequenos estímulos na atividade da RN foram observados (Klotz \& Horst, 1988).

Segundo Mendonça et al. (2005), o ajuste do balanço de prótons e a modificação do $\mathrm{pH}$ da solução nutritiva, por duas cultivares de arroz com tolerância diferencial ao $\mathrm{Al}$, foram coerentes com diferenças no sistema de transporte e redução do nitrato dessas plantas. Poucos trabalhos, entretanto, têm procurado estudar os efeitos do $\mathrm{Al}$, seja sobre a absorção, a redução do nitrato ou outro aspecto do metabolismo de $\mathrm{N}$ em arroz, especialmente no Brasil.

O objetivo deste trabalho foi avaliar os efeitos do $\mathrm{Al}$ sobre a absorção e a redução de nitrato, em duas cultivares nacionais de arroz, na tentativa de entender o modo de ação do $\mathrm{Al}$ nessas plantas.

\section{Material e Métodos}

Foram utilizadas duas cultivares de arroz (Oryza sativa L.) com tolerância diferencial ao Al: uma tolerante (Fernandes: CNA-1158) e outra sensível (Maravilha: CNA-6843-1) (Fageria et al., 1988), fornecidas pela Embrapa Arroz e Feijão, em Santo Antônio de Goiás, GO.

As sementes, selecionadas quanto ao tamanho e forma, foram tratadas com $\mathrm{H}_{2} \mathrm{SO}_{4}$ a $50 \%$, por 15 minutos, lavadas em água corrente, esterilizadas superficialmente, por tratamento com hipoclorito de sódio a $2 \%$, por 15 minutos, e lavadas novamente em água corrente e em água desmineralizada. A seguir, foram colocadas para germinar em cartuchos de papel germiteste, conforme descrito por Mendonça et al. (2005).

Plântulas de sete dias de idade, selecionadas quanto à uniformidade de tamanho e forma, foram transplantadas para vasos de polietileno, com 1,6 L de solução nutritiva de Clark, pH 4,0 (Clark, 1975). Os tratamentos consistiram na aplicação de $\mathrm{Al}$ nas concentrações de 0 e $500 \mu \mathrm{M}$, na forma de $\mathrm{AlCl}_{3} \cdot 6 \mathrm{H}_{2} \mathrm{O}$, com o pH da solução nutritiva ajustado diariamente para 4, utilizando-se $\mathrm{NaOH} 0,1 \mathrm{~N}$ ou $\mathrm{HCl} 0,1 \mathrm{~N}$.

Depois de 21 dias de exposição ao $\mathrm{Al}$, as plantas foram colhidas e os comprimentos da maior raiz e da parte aérea foram determinados. As plantas foram, então, lavadas em $\mathrm{HCl} 0,1 \mathrm{~N}$, por cinco minutos, em água corrente e em água desmineralizada e foram colocadas para secar em estufa a $70^{\circ} \mathrm{C}$ até obtenção de massa constante. O material vegetal seco foi pulverizado em almofariz elétrico, em cápsula de aço inox, mineralizado numa mistura nítrico-perclórica e, no extrato mineral, foram determinados os teores de $\mathrm{Al}$, pelo método da aluminona (Wang \& Wood, 1973), e os de nitrato por nitração com ácido salicílico (Cataldo et al., 1975).

Para a determinação da absorção de nitrato, usaram-se plântulas de sete dias de idade, obtidas conforme descrito anteriormente. Após 13 dias de tratamento com 0 e $500 \mu \mathrm{M}$ de $\mathrm{Al}$, as plantas foram transferidas para vasos com $500 \mathrm{~mL}$ de solução nutritiva modificada, contendo os mesmos tratamentos, mas com o $\mathrm{N}$ fornecido exclusivamente na forma de nitrato, na concentração de $100 \mu \mathrm{M}$. As plantas permaneceram nestas soluções por 24 horas, e as soluções nutritivas 
foram renovadas a cada quatro horas, para a obtenção do equilíbrio dinâmico.

Encerrado esse período, após a lavagem do sistema radicular com água desmineralizada, as plantas foram transferidas para novos vasos contendo $500 \mathrm{~mL}$ da mesma solução nutritiva anterior, com seus respectivos tratamentos. A partir daí, alíquotas de $1 \mathrm{~mL}$ do meio de cultivo passaram a ser periodicamente coletadas. No início, em intervalos de 15 minutos, até se completarem duas horas e, então, em intervalos de uma hora, até o final do experimento, quando ocorreu o esgotamento do nitrato da solução nutritiva. A redução do volume pela retirada das alíquotas foi compensada pela adição de igual volume de água desmineralizada.

No final do experimento, os sistemas radiculares foram destacados, lavados e colocados para secar até obtenção de massa constante. A concentração de nitrato nas alíquotas coletadas foi determinada espectrofotometricamente, a $210 \mathrm{~nm}$ (Cawse, 1967). As constantes cinéticas $V_{\max }$ e $K_{m}$ para absorção de nitrato foram avaliadas segundo Claassen \& Barber (1974) e estimadas pela aproximação gráfico-matemática sugerida por Ruiz (1985).

Para a avaliação da atividade da RN, usaram-se plântulas de sete dias de idade, obtidas conforme descrito anteriormente. Depois de 13 dias de tratamento com $\mathrm{Al} 0$ e $500 \mu \mathrm{M}$, as plantas foram transplantadas para soluções nutritivas com os mesmos tratamentos, modificadas para conter todo o $\mathrm{N}$ na forma nítrica, e passaram a receber luz contínua.

Vinte e quatro horas depois, o experimento foi encerrado, e foi determinada a atividade in vitro da RN nas duas partes da planta. Amostras de folhas e raízes foram trituradas em nitrogênio líquido e homogeneizadas em meio constituído de tampão tris- $\mathrm{HCl} 0,1 \mathrm{M}$, pH 8,1, $\mathrm{NiSO}_{4} 4 \mathrm{mM}$ e glutationa reduzida $20 \mathrm{mM}$. Os extratos brutos foram filtrados através de quatro camadas de gaze e centrifugados a $15.000 \mathrm{~g}$ durante 15 minutos, usando- se o sobrenadante para a determinação da atividade enzimática.

Alíquotas de 0,2 mL do extrato enzimático foram adicionadas a $1,8 \mathrm{~mL}$ do meio de reação constituído de $200 \mu$ mol de tampão tris-HCl, pH 7,5, $20 \mu$ mol de $\mathrm{KNO}_{3}, 0,1 \mu \mathrm{mol}$ de $\mathrm{NADH}$ e $0,1 \mathrm{~mL}$ de triton $\mathrm{X}-1001 \%(\mathrm{p} / \mathrm{v})$. A mistura foi incubada a $30^{\circ} \mathrm{C}$ durante 10 minutos e, então, a reação foi interrompida pela adição de $2 \mathrm{~mL}$ de sulfanilamida $1 \%$ (v/v), em mistura com N-naftil etilenodiamino 0,01\% (v/v) em HCl 1,0 M. O nitrito produzido foi determinado por espectrofotometria do visível a $540 \mathrm{~nm}$, e a atividade enzimática expressa em $\mu$ mol de $\mathrm{NO}_{2}^{-} \mathrm{h}^{-1} \mathrm{~g}^{-1}$ de matéria fresca (Cambraia et al., 1989).

Todos os experimentos foram realizados em sala de crescimento, com temperatura e luminosidade controladas ( $25 \pm 2^{\circ} \mathrm{C}, 230 \mu \mathrm{mol} \mathrm{m} \mathrm{m}^{-2} \mathrm{~s}^{-1}$ ), sob fotoperíodo de 16 horas. Seguiu-se, em todos os experimentos, esquema fatorial, no delineamento de blocos ao acaso, com três repetições. Os resultados foram submetidos à análise de variância, e as médias comparadas pelo teste de Tukey a 5\% de probabilidade.

\section{Resultados e Discussão}

A cultivar Fernandes (tolerante) apresentou maior crescimento, tanto da parte aérea quanto das raízes, independentemente da presença de Al (Tabela 1). $\mathrm{Na}$ presença de $\mathrm{Al}$, o comprimento da parte aérea da cultivar Maravilha (sensível) sofreu redução de 10,1\% e o das raízes de $26,2 \%$, enquanto na tolerante não foram observados efeitos significativos em nenhuma das partes da planta.

Duas cultivares asiáticas de arroz, submetidas ao $\mathrm{Al}$ na concentração de $222 \mu \mathrm{M}$, durante 30 dias, apresentaram redução de $22 \%$ no comprimento das raízes na cultivar sensível e de 8\% na tolerante (Ganesan et al., 1993).

Tabela 1. Efeito do Al sobre o crescimento e os teores de Al e de nitrato, em duas partes das plantas de duas cultivares de $\operatorname{arroz}^{(1)}$.

\begin{tabular}{|c|c|c|c|c|c|c|c|c|c|}
\hline \multirow[t]{2}{*}{ Cultivar } & \multirow[t]{2}{*}{$\mathrm{Al}(\mu \mathrm{M})$} & \multicolumn{2}{|c|}{ Comprimento $(\mathrm{cm})$} & \multicolumn{2}{|c|}{$\begin{array}{c}\text { Matéria seca } \\
\text { (g por } 2 \text { plantas) }\end{array}$} & \multicolumn{2}{|c|}{$\mathrm{Al}\left(\mathrm{mg} \mathrm{g}^{-1} \mathrm{MS}\right)$} & \multicolumn{2}{|c|}{ Nitrato $\left(\mathrm{mg} \mathrm{g}^{-1} \mathrm{MS}\right)$} \\
\hline & & Parte aérea & Raízes & Parte aérea & Raízes & Parte aérea & Raízes & Parte aérea & Raízes \\
\hline \multirow[t]{2}{*}{ Fernandes } & 0 & $56,7 \mathrm{Aa}$ & $45,0 \mathrm{Aa}$ & $0,223 \mathrm{Aa}$ & $0,094 \mathrm{Aa}$ & $0,23 \mathrm{Ba}$ & $0,50 \mathrm{Ba}$ & $20,5 \mathrm{Aa}$ & $39,7 \mathrm{Aa}$ \\
\hline & 500 & $56,2 \mathrm{Aa}$ & $44,7 \mathrm{Aa}$ & $0,206 \mathrm{Aa}$ & $0,089 \mathrm{Aa}$ & $0,32 \mathrm{Aa}$ & $2,52 \mathrm{Aa}$ & $19,2 \mathrm{Aa}$ & $45,9 \mathrm{Aa}$ \\
\hline \multirow[t]{2}{*}{ Maravilha } & 0 & $43,7 \mathrm{Ab}$ & $42,3 \mathrm{Ab}$ & $0,093 \mathrm{Ab}$ & $0,041 \mathrm{Ab}$ & $0,08 \mathrm{Bb}$ & $0,50 \mathrm{Ba}$ & $22,9 \mathrm{Aa}$ & $37,2 \mathrm{Aa}$ \\
\hline & 500 & $39,3 \mathrm{Bb}$ & $31,2 \mathrm{Bb}$ & $0,044 \mathrm{Bb}$ & $0,024 \mathrm{Bb}$ & $0,29 \mathrm{Aa}$ & $2,67 \mathrm{Aa}$ & $21,1 \mathrm{Aa}$ & $25,4 \mathrm{Bb}$ \\
\hline
\end{tabular}

(1)Médias seguidas por letras iguais, maiúsculas entre os níveis de Al e minúsculas entre as cultivares, para cada parte da planta e para cada variável avaliada, não diferem entre si a 5\% de probabilidade, pelo teste de Tukey. 
Sivaguru \& Paliwal (1993) trataram 22 cultivares, de vários países asiáticos, com diferentes concentrações de $\mathrm{Al}$ e encontraram de ligeiros aumentos até reduções severas no crescimento da parte aérea e das raízes.

Resultados como esses mostram que, além das diferenças genotípicas, a concentração e o tempo de exposição ao $\mathrm{Al}$, entre outros possíveis fatores experimentais, influenciam fortemente as respostas das plantas e, portanto, devem ser rigorosamente controlados e relatados na descrição experimental.

A cultivar Fernandes, considerada mais tolerante ao $\mathrm{Al}$, apresentou na presença deste íon crescimento da parte aérea e das raízes, em média, 30\% maior do que a Maravilha, o que corrobora resultados anteriores obtidos por Mendonça et al. (2005).

Similarmente ao que aconteceu em termos de crescimento, apenas a cultivar Maravilha teve redução significativa na produção de matéria seca, na presença de níveis tóxicos de $\mathrm{Al}$ (Tabela 1), que foi de 52,7\% e de 41,5\% na parte aérea e nas raízes, respectivamente, ficando 78,6 e 73\% menor do que na cultivar Fernandes. Assim, na presença de níveis tóxicos de $\mathrm{Al}$ a cultivar sensível produziu menos do que a tolerante, resultado que confirma os dados obtidos por Mendonça et al. (2005), que utilizaram as mesmas cultivares de arroz deste tabalho, e os obtidos por Ganesan et al. (1993) que utilizaram cultivares asiáticas de arroz.

Os teores de $\mathrm{Al}$ aumentaram, significativamente, depois do tratamento das plantas com esse elemento, tanto na parte aérea quanto nas raízes das duas cultivares (Tabela 1). Na parte aérea, o teor de $\mathrm{Al}$ aumentou em média 97\%, e nas raízes em cerca de cinco vezes com o tratamento com Al. As cultivares não diferiram entre si quanto ao teor de $\mathrm{Al}$, exceto quanto à parte aérea dos controles, em que a cultivar Fernandes apresentou teor mais elevado de Al. Mendonça et al. (2005) trabalharam com as mesmas cultivares de arroz utilizadas neste trabalho, entretanto não encontraram diferenças entre as plantas controles das duas cultivares. A análise das sementes utilizadas no experimento mostrou teores extremamente baixos de $\mathrm{Al}$, e nenhuma diferença entre as cultivares foi detectada. A possibilidade de erro na determinação foi investigada, mas análises posteriores dos mesmos materiais confirmaram os resultados. Os teores de $\mathrm{Al}$ nas duas partes da planta foram parecidos com aqueles encontrados nessas e outras cultivares de arroz por outros autores (Fageria et al., 1988; Sivaguru \& Paliwal, 1993; Mendonça et al., 2005).

Os teores de $\mathrm{Al}$ observados neste trabalho, à semelhança do obtido por Ganesan et al. (1993) com duas cultivares de arroz com tolerância diferencial ao
Al, também não se correlacionaram com a tolerância dessas cultivares ao $\mathrm{Al}$ em termos de crescimento de raízes e parte aérea. A análise das formas e da localização do Al, nas células e tecidos, talvez possa indicar, com mais clareza, diferenças entre as cultivares quanto à tolerância ao $\mathrm{Al}$.

Os teores de nitrato não foram influenciados pela presença de Al, exceto nas raízes da cultivar Maravilha, em que se observou decréscimo significativo de 32\% (Tabela 1). A cultivar tolerante, na presença de Al, apresentou $81 \%$ mais nitrato em suas raízes do que a cultivar sensível. Ganesan et al. (1993), após exposição de duas cultivares de arroz da Índia a $222 \mu \mathrm{M}$ de Al, durante duas semanas, observaram reduções de 27 e $52 \%$ nos teores de nitrato das partes aéreas das cultivares tolerante e sensível, respectivamente, comprovando a maior sensibilidade das cultivares asiáticas em relação às brasileiras.

Na faixa de concentração de nitrato de 0 a $100 \mu \mathrm{M}$, não foram observadas diferenças entre as cultivares quanto à velocidade máxima $\left(\mathrm{V}_{\max }\right)$ de absorção de nitrato, e o $\mathrm{Al}$ não modificou o valor dessa constante cinética (Tabela 2). As duas cultivares de arroz, entretanto, apresentaram diferenças significativas com relação ao valor da constante de Michaelis-Menten $\left(\mathrm{K}_{\mathrm{m}}\right)$, que mede a afinidade do sistema de absorção de nitrato (Tabela 2).

Na ausência de Al, a cultivar Fernandes apresentou $K_{m}$ cerca de $15 \%$ maior que a sensível. Na presença de $\mathrm{Al}$, o $\mathrm{K}_{\mathrm{m}}$ da absorção de nitrato na cultivar Fernandes foi reduzido cerca de $11 \%$, enquanto na Maravilha foi aumentado mais de $300 \%$. Nesta condição, portanto, a cultivar Maravilha passou a ter $\mathrm{K}_{\mathrm{m}}$ cerca de três vezes maior que a tolerante.

A cultivar Maravilha embora tivesse apresentado maior afinidade por nitrato que a Fernandes na ausência de $\mathrm{Al}$, na presença desse elemento passou a ter afinidade muito menor, tendo perdido capacidade de absorver esse ânion em soluções mais diluídas. Assim, a absorção de

Tabela 2. Efeito do Al sobre as constantes cinéticas de absorção de nitrato de duas cultivares de $\operatorname{arroz}^{(1)}$.

\begin{tabular}{lccc}
\hline Cultivar & $\mathrm{Al}$ & \multicolumn{2}{c}{ Constantes cinéticas } \\
\cline { 2 - 4 } & & $\begin{array}{c}\mathrm{V}_{\max } \\
(\mu \mathrm{M})\end{array}$ & $\begin{array}{c}\mathrm{K}_{\mathrm{m}} \\
(\mu \mathrm{M})\end{array}$ \\
\hline Fernandes & 0 & $23,34 \mathrm{Aa}$ & $23,50 \mathrm{Aa}$ \\
& 500 & $21,35 \mathrm{Aa}$ & $20,93 \mathrm{Bb}$ \\
\hline Maravilha & 0 & $19,41 \mathrm{Aa}$ & $20,49 \mathrm{Bb}$ \\
& 500 & $22,13 \mathrm{Aa}$ & $62,89 \mathrm{Aa}$ \\
\hline
\end{tabular}

(1)Médias nas colunas seguidas por letras iguais, maiúsculas entre os níveis de $\mathrm{Al}$ e minúsculas entre as cultivares, não diferem entre si a 5\% de probabilidade, pelo teste de Tukey. 
nitrato, estimada com base nessas constantes cinéticas (Tabela 1), para a concentração utilizada de $100 \mu \mathrm{M}$, sofreu redução de aproximadamente $15 \%$ na cultivar Maravilha, tendo permanecido inalterada na cultivar Fernandes.

Vários trabalhos têm demonstrado o efeito do $\mathrm{Al}$ sobre a absorção de nitrato. Esses resultados, contudo, se mostram controversos. Em vários genótipos de milho (Durieux et al., 1993; Purcino et al., 2003) e de sorgo (Keltjens \& Ulden, 1987; Cambraia et al., 1989), têm sido verificadas reduções na absorção de nitrato. Em cevada, entretanto, foi observado aumento de 44\% na absorção de nitrato (Nichol et al., 1993). Nesse caso, os autores sugerem que o $\mathrm{Al}$ se ligaria a fosfolipídios da membrana plasmática, formando uma camada de carga positiva que facilitaria a passagem de ânions por essa membrana.

Neste trabalho, contudo, apesar de as plantas terem sido expostas durante 21 dias, o principal efeito do $\mathrm{Al}$ foi sobre o $\mathrm{K}_{\mathrm{m}}$, isto é, sobre a configuração da proteína transportadora, o que modificou a afinidade do sítio de ligação pelo nitrato. Não se observou efeito significativo sobre $\mathrm{V}_{\max }$ pois, possivelmente, o $\mathrm{Al}$ não teve influência sobre a biossíntese de transportadores. Os resultados aqui obtidos corroboram os de Mendonça et al. (2005) que mostraram que a cultivar Fernandes, sob níveis tóxicos de $\mathrm{Al}$, retornou $68,3 \%$ mais prótons para o simplasma do que a Maravilha, forte indicativo de interferência do $\mathrm{Al}$ no simporte $\mathrm{H}^{+} / \mathrm{NO}_{3}$ ( (Tischner, 2000), que realiza a absorção de nitrato na faixa de concentração estudada.

A atividade in vitro da RN na cultivar Maravilha, na presença de $\mathrm{Al}$, sofreu redução de cerca de 46 e $12 \%$ na parte aérea e nas raízes, respectivamente, enquanto na Fernandes observou-se redução de $14 \%$ na atividade dessa enzima somente nas raízes (Figura 1).

A atividade da RN na cultivar Fernandes foi sempre maior do que na Maravilha, independentemente da parte da planta analisada e da presença de Al. Na presença de $\mathrm{Al}$ a parte aérea das plantas da cultivar Fernandes chegou a ter atividade da RN 61\% maior do que a da cultivar Maravilha. De modo semelhante, foram observadas reduções de 12 e 37\% na atividade dessa enzima, em folhas de duas cultivares asiáticas de arroz com tolerância diferencial ao Al (Ganesan et al., 1993), que comprometeram todo o metabolismo de $\mathrm{N}$ (Kochian et al., 2004).

A atividade da RN na cultivar Fernandes foi aproximadamente igual nas duas partes da planta (Figura 1). Na cultivar Maravilha, entretanto, a atividade dessa enzima foi maior nas raízes, chegando a ser $45 \%$ maior

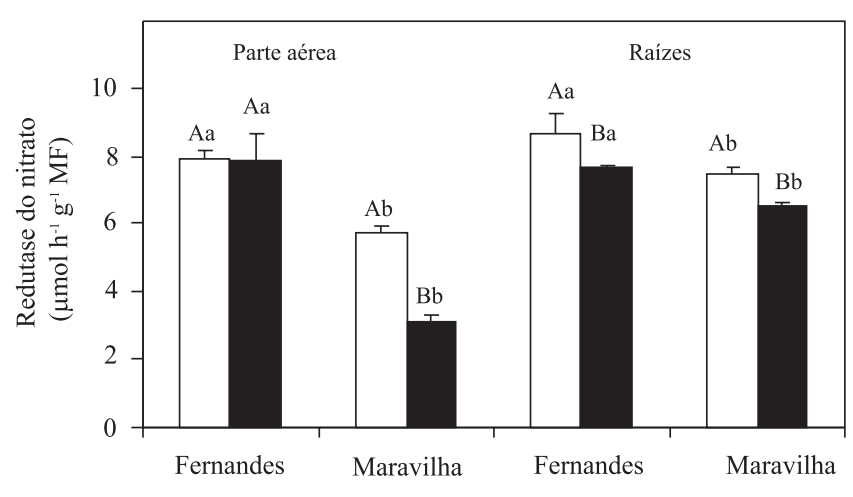

Figura 1. Efeito do alumínio sobre a atividade in vitro da redutase do nitrato, em duas cultivares de arroz, em solução nutritiva, pH 4. $\square: 0 \mu \mathrm{M}$ de Al e $\mathbf{~}: 500 \mu \mathrm{M}$ de Al.

do que na parte aérea nas plantas tratadas com Al. Apesar disso, a maior diferença entre as cultivares, quanto à atividade dessa enzima, ocorreu na parte aérea, o que sugere ser esta parte da planta a mais conveniente para estudos de discriminação de cultivares de arroz quanto à tolerância ao alumínio.

A cultivar Maravilha apresentou, na presença de Al, menor absorção, menor redução na parte aérea e menor acúmulo de nitrato nas raízes do que a cultivar Fernandes, o que comprometeu seriamente todo seu metabolismo de N. Embora alguns autores sejam enfáticos em afirmar que essa resposta diferencial pode ser tomada como evidência de um mecanismo de tolerância ao Al (Ganesan et al., 1993), talvez o mais prudente seja admitir que a absorção e a redução do nitrato podem ser importantes componentes do mecanismo de tolerância ao $\mathrm{Al}$ em arroz.

\section{Conclusões}

1. $\mathrm{O} A l$ não modifica o $\mathrm{V}_{\max }$ nas duas cultivares de arroz, mas aumenta o $\mathrm{K}_{\mathrm{m}}$ na cultivar Maravilha, reduzindo a absorção de nitrato apenas nessa cultivar.

2. O Al reduz a atividade in vitro da redutase do nitrato nas raízes, nas duas cultivares, mas, na parte aérea, apenas na cultivar Maravilha.

3. A cultivar Fernandes apresenta maior eficiência, tanto na absorção quanto na redução do nitrato, em comparação à cultivar Maravilha.

\section{Agradecimentos}

Ao CNPq, pelas bolsas de produtividade concedidas; à Embrapa Arroz e Feijão, pelo fornecimento das sementes. 


\section{Referências}

AHN, S.J.; SIVAGURU, M.; CHUNG, G.C.; RENGEL, Z.; MATSUMOTO, H. Aluminium-induced growth inhibition is associated with impaired efflux and influx of $\mathrm{H}^{+}$across the plasma membrane in root apices of squash (Cucurbita pepo). Journal of Experimental Botany, v.53, p.1959-1966, 2002.

CAMBRAIA, J.; PIMENTA, J.A.; ESTEVÃO, M.M.; SANT'ANNA, R. Aluminum effects on nitrate uptake and reduction in sorghum. Journal of Plant Nutrition, v.12, p.1435-1445, 1989. CATALDO, D.A.; HAROON, M.; SCHRADER, L.E.; YOUNGS, V.L. Rapid colorimetric determination of nitrate in plant tissue by nitration of salicylic - acid. Communications in Soil Science and Plant Analysis, v.6, p.71-80, 1975.

CAWSE, P.A. The determination of nitrate in soil solutions by ultraviolet spectrophotometry. Analyst, v.92, p.311-315, 1967.

CLAASSEN, N.; BARBER, S.A. A method for characterizing the relation between nutrient concentration and flux into roots of intact plants. Plant Physiology, v.54, p.564-568, 1974.

CLARK, R.B. Characterization of phosphatase of intact maize roots. Journal of Agricultural and Food Chemistry, v.23, p.458-460, 1975.

DEGENHARDT, J.; LARSEN, P.B.; HOWELL, S.H.; KOCHIAN, L.V. Aluminum resistance in the Arabidopsis mutant alr-104 is caused by an aluminum-induced increase in rhizosphere pH. Plant Physiology, v.117, p.19-27, 1998.

DURIEUX, R.P.; JACKSON, W.A.; KAMPRATH, E.J.; MOLL, R.H. Inhibition of nitrate uptake by aluminium in maize. Plant and Soil, v.151, p.97-104, 1993.

FAGERIA, N.K.; WRIGHT, R.J.; BALIGAR, V.C. Rice cultivars response to aluminum in nutrient solution. Communications in Soil Science and Plant Analysis, v.19, p.1133-1142, 1988.

GANESAN, K.; SANKARANARAYANAN, C.; BALAKUMAR, T. Physiological basis of differential aluminum tolerance in rice genotypes. Communications in Soil Science and Plant Analysis, v.24, p.2179-2191, 1993.

JONES, D.L.; KOCHIAN, L.V. Aluminum inhibition of the inositol 1,4,5-triphosphate signal transduction pathway in wheat roots: a role in aluminum toxicity? Plant Cell, v.7, p.1913-1922, 1995.

KELTJENS, W.G.; ULDEN, P.S.R. van. Effects of Al and nitrogen $\left(\mathrm{NH}_{4}{ }^{+}\right.$and $\left.\mathrm{NO}_{3}{ }^{-}\right)$uptake, nitrate reductase activity and proton release in two sorghum cultivars differing in Al tolerance. Plant and Soil, v.104, p.227-234, 1987.

KLOTZ, F.; HORST, W.J. Genotypic differences in aluminum tolerance of soybean (Glycine max L.) as affected by ammonium and nitrate-nitrogen nutrition. Journal of Plant Physiology, v.132, p.702-707, 1988.
KOCHIAN, L.V.; HOEKENGA, O.A.; PIÑEROS, M.A. How do crop plants tolerate acid soils? Mechanisms of aluminum tolerance and phosphorous efficiency. Annual Review of Plant Biology, v.55, p.459-493, 2004.

LLUGANY, M.; POSCHENRIEDER, C.; BARCELÓ, J. Monitoring of aluminum-induced inhibition of root elongation in four maize cultivars differing in tolerance to aluminum and proton toxicity. Physiologia Plantarum, v.93, p.265-271, 1995.

LOPES, A.S. Solos sob “cerrado”: características, propriedades e manejo. Piracicaba: Associação Brasileira para Pesquisa da Potassa e do Fosfato, 1984. 162p.

MENDONÇA, R.J. de; CAMBRAIA, J.; OLIVA, M.A.; OLIVEIRA, J.A. de. Capacidade de cultivares de arroz de modificar o pH de soluções nutritivas na presença de alumínio. Pesquisa Agropecuária Brasileira, v.40, p.447-452, 2005.

NICHOL, B.E.; OLIVEIRA, L.A.; GLASS, A.D.M.; SIDDIQI, M.Y. The effects of aluminum on the influx of calcium, potassium, ammonium, nitrate, and phosphate in an aluminum-sensitive cultivar of barley (Hordeum vulgare L.). Plant Physiology, v.101, p.12631266, 1993.

PURCINO, A.A.C.; ALVES, V.M.C.; PARENTONI, S.N.; BELELE, C.L.; LOGUERCIO, L.L. Aluminum effects on nitrogen uptake and nitrogen assimilating enzymes in maize genotypes with contrasting tolerance to aluminum toxicity. Journal of Plant Nutrition, v.26, p.31-61, 2003.

ROUT, G.R.; SAMANTARAY, S.; DAS, P. Aluminium toxicity in plants: a review. Agronomie, v.21, p.3-21, 2001.

RUFTY JUNIOR, T.W.; MacKOWN, C.T.; LAZOF, D.B.; CARTER, T.E. Effects of aluminium on nitrate uptake and assimilation. Plant, Cell and Environment, v.18, p.1325-1331, 1995.

RUIZ, H.A. Estimativa dos parâmetros cinéticos $\mathrm{K}_{\mathrm{m}} \mathrm{e} \mathrm{V}_{\max }$ por uma aproximação gráfico-matemática. Revista Ceres, v.32, p.79-84, 1985.

SIVAGURU, M.; PALIWAL, K. Differential aluminum tolerance in some tropical rice cultivars. I. Growth-performance. Journal of Plant Nutrition, v.16, p.1705-1716, 1993.

TISCHNER, R. Nitrate uptake and reduction in higher and lower plants. Plant, Cell and Environment, v.23, p.1005-1024, 2000.

WANG, C.; WOOD, F.A. A modified aluminon reagent for determination of aluminum after $\mathrm{HNO}_{3}-\mathrm{H}_{2} \mathrm{SO}_{4}$ digestion. Canadian Journal of Soil Science, v.53, p.237-239, 1973.

YAMAMOTO, Y.; HOBAYASHI, Y.; DEVI, S.R.; RIKIISHI, S. Aluminum toxicity is associated with mitochondrial dysfunction and the production of reactive oxygen species in plant cells. Plant Physiology, v.128, p.63-72, 2002. 